ICES Journal of Marine Science

AUGUST 2000; 57(4) : 1160-1174

http://dx.doi.org/10.1006/imsc.2000.0803

Copyright ( 2000 International Council for the Exploration of

the Sea. All rights reserved
Archimer http://www.ifremer.fr/docelec/ Archive Institutionnelle de l'Ifremer

\title{
Does the concept of spawning per recruit make sense?
}

\author{
Marie-Joëlle Rochet * \\ Laboratoire MAERHA, IFREMER, Rue de l'Ile d'Yeu, B.P. 21105, 44311, Nantes Cedex 03, France \\ *e-mail: mjrochet@ifremer.fr
}

\begin{abstract}
:
Density dependence means that exploited fish populations exhibit earlier maturity, a faster growth rate, increased fecundity and reduced egg size. Here, the consequences of these effects on population dynamics, the estimation of spawning biomass per recruit and associated biological reference points are examined by a simulation model. The model is a self-regenerating model in which the population parameters (age at maturity, growth, fecundity, egg size) vary according to three classes of population abundance. Early life stages are characterized by a size-dependent growth and mortality model. It is concluded that spawning per recruit is an ambiguous concept because, if density dependence occurs in the adult population, the spawning biomass of a cohort is not proportional to the number recruited. This leads to significant level of uncertainty in the estimates of spawning biomass per recruit and the associated biological reference points such as $F_{\text {low }}, F_{\text {med }}, F_{\text {high }}$ and VSPR.
\end{abstract}

Keywords: biological reference points, density-dependence, life history, population dynamics, teleost fishes 


\section{Introduction}

Biological Reference Points are increasingly used for fisheries management. They make a link between management objectives and the characteristics of the fishery (Caddy and Mahon, 1996). Therefore the underlying mathematical models must be as realistic as possible regarding those characteristics of the fishery that are considered important for the management objectives.

Several of the widely used Biological Reference Points (BRP) include recruitment considerations, either by means of a spawner-recruit model, or by considering the spawning biomass per recruit, or both. Such BRP's are designed to avoid recruitment overfishing, which may occur when a population has been exploited to the point where recruitment is substantially reduced (Sissenwine and Shepherd, 1987). For any fishing mortality rate F, a recruited cohort is expected to produce a spawning biomass proportional to the number recruited. The ratio of this biomass to recruitment, spawning per recruit (SPR), can be expressed as a percentage of the virgin SPR, and the associated F, designated $\mathrm{F}_{\mathrm{x} \%}$, can be used as a BRP (Mace and Sissenwine, 1993). Moreover, for any F there is a single straight line through the origin of the stock-recruitment plot. The slope of this line is the inverse of the spawning biomass per recruit which corresponds to the F level (Shepherd, 1982). The more heavily the stock is exploited, the lower the spawning biomass per recruit, hence the steeper the slope. This line is called a replacement line because it defines the survivorship needed to replace the spawning stock in the future (Sissenwine and Shepherd, 1987). Replacement lines are combined with a spawner-recruit function to define $\mathrm{F}_{\mathrm{msy}}$, a well-known $\mathrm{BRP}$, and $\mathrm{F}_{\text {crash, }}$ the fishing mortality which results in stock collapse (Shepherd, 1982). On the other hand, if a spawner-recruit function is not known, replacement lines can also be combined with the observed series of stock-recruitment points to define widely used BRP's such as $F_{\text {rep }}, F_{\text {med }}, F_{\text {low }}$ and $F_{\text {high }}$ (Sissenwine and Shepherd, 1987; Anonymous, 1991), and $F_{\text {loss }}$ used as a lower bound estimate for $\mathrm{F}_{\text {crash }}(\mathrm{Cook}, 1998)$. All these BRP's are widely used (Caddy and Mahon, 1996; Anonymous, 1997; Deriso et al., 1998). Moreover, some of them are involved in the definition of limit reference points used in the precautionary approach (Anonymous, 1997; Anonymous, 1998a). SPR and replacement lines are important concepts in modern fisheries management.

A replacement line is dependent on a number of biological parameters such as growth, maturity and natural mortality, and estimates of these quantities are required to calculate SPR for a stock 
(Shepherd, 1982; Cook, 1998). Whereas it was previously thought that density-dependent control of fish populations only occurs during the early years of life (Ricker, 1954; Beverton and Holt, 1957; Shepherd and Cushing, 1980), it is more and more recognised that adult stages may also be regulated by density-dependent mechanisms (e.g. Ware, 1985; Horwood et al., 1986 ; Rijnsdorp, 1994; Trippel, 1995; Rochet, 1998). As population density decreases, growth rate increases, maturity is achieved earlier, fecundity at a given size is higher, and as a result of the younger age of mothers, egg size decreases. Therefore we may ask whether these mechanisms can have an impact on SPR calculations. For a given fishing mortality, can we assume that spawning per recruit will be equal for any recruitment? Or will compensation mechanisms make spawning per recruit decrease as recruitment increases? What is the impact of these compensation mechanisms on our estimates of biological reference points?

This kind of question deserves more than a qualitative answer. It is desirable to quantify this impact to assess the importance of compensation mechanisms among the various uncertainties that affect BRP estimates. For that purpose, the difficulty is to obtain reliable estimates of compensatory effects. Density-dependent effects are difficult to measure precisely because of the concomitant influence of environmental factors (Pitt, 1975; Hempel, 1978; Kotilainen and Aro, 1991; Rijnsdorp et al., 1991; Jakobsen, 1992; Parmanne, 1992; Rijnsdorp and van Leeuwen, 1992). Despite this difficulty, simple compensation functions (such as linear or log-linear models) have been fitted to historic weight-atage, maturity-at-age and stock biomass or abundance data for Atlantic mackerel (Overholtz et al., 1991), spring-spawning herring (Patterson, 1997) and silver hake (Helser and Brodziak, 1998). These fitted functions were subsequently used in stock projections. All three studies concluded that the classical density-independent models yield over-optimistic and risky assessments compared to alternative density-dependent models. The question is, how general are these results? Moreover, the conclusions may have been affected by environmental changes and autocorrelated time-series data. Can we establish such results, free of this kind of errors?

This paper presents an alternative approach to incorporating density-dependence into SPR calculations by using estimates of fishing effects from a comparative approach (Rochet et al., Submitted). A new method was developed to estimate fishing effect from environments contrasted on the basis of fishing pressure. The comparison of demographic parameters included 84 populations of 
49 species subject to various degrees of fishing pressure. It was concluded that increasing fishing pressure significantly decreases age at maturity and average egg size, and increases fecundity at maturity, the slope of the fecundity-length relationship and relative size at maturity. These estimates are considered valid for many exploited species of Teleost, and free of environmental influence such as temperature or biotic interactions thanks to the comparative approach. Here it is assumed that these effects occurred by compensatory mechanisms. The estimates are used as parameters of densitydependent mechanisms and incorporated into a self-regenerating model. This model is used for spawning per recruit analyses and BRP computations for stocks with different life history strategies (cod, sole, sardine), in order to assess the impact of these mechanisms on SPR and BRP's.

\section{Materials and methods}

\section{1) A self-regenerating population model}

There are two components in the population model: an age-structured model for adults, and a sizebased model for the early life stages (Fig. 1). For the adult stock, the population numbers $N_{a, t}$ at age $a$, in year $t$, are calculated from:

$$
N_{a, t}=N_{a-1, t-1} e^{-M_{a-1}-F_{a-1}}
$$

with $F_{a}$ and $M_{a}$ instantaneous fishing and mortality rates (assumed invariant with time). The eggproduction of the population, $N_{e, t}$, is calculated from i) the proportion mature at age (maturity ogive) according to a normal or exponential distribution with mean $A_{m}$ and standard deviation $\sigma_{A_{m}}$ $V_{a, t} \sim N\left(A_{m}, \sigma_{A_{m}}\right)$ ii) the fecundity-length relationship $E_{a}=E L_{a}^{b}$ (2) where $E$ and $b$ are constants, and

iii) the vector of length-at-age $L_{a, t}$ calculated from the initial length $L_{1, t}$ using a vector of length increments $\Delta L: \quad L_{a, t}=L_{a-1, t-1}+\Delta L_{a-1}$. The number of eggs produced in year $t$ is $N_{e, t}=\sum_{a} N_{a, t} V_{a, t} E L_{a, t}^{b} \quad$ (3). The weight of these eggs is $W_{e, t}$.

To derive recruitment in year $t+1$ from $N_{e, t}$ and $W_{e, t}$, early life stages are described by a sizedependent model for several reasons. Firstly, egg size is known to influence egg and larval survival and growth abilities (Rijnsdorp and Jaworski, 1990; Miller et al., 1992; Brooks et al., 1997; Trippel, 1998). Secondly, there is growing concern that fishing affects egg size and quality by changing the age and size of mothers (Kjesbu et al., 1996; Reznick et al., 1996; Chambers, 1997; Solemdal, 1997; Trippel et al., 1997; MacKenzie et al., 1998; Marshall et al., 1998; Trippel, 1998). Thirdly, body size is often used 
for scaling predation processes (Ware, 1978; Silvert and Platt, 1980) and all vital rates (Ware, 1975; Pepin, 1991; Houde, 1997); therefore body size might be of primary importance for understanding recruitment dynamics (Beyer, 1989). Here it is assumed that variations in egg weight will result in variations in recruitment. According to Ware (1975), if growth is allometric $\left(\frac{d W}{d t}=r W^{1-m}\right)$, and if growth and mortality rates are proportional $\left(\frac{d N}{d t}=-q W^{-m} N\right)$, then the number $N_{0, t}$ of eggs that survive the incubation period (duration $I$ ) and hatch is: $N_{0, t}=N_{e, t} e^{-I q W_{e, t}^{-m}}$ (4). The weight of these newly hatched larvae is $W_{0, t}=p W_{e, t}$, where $p$ is a constant. They recruit to the population at weight $W_{1, t+1}$ and abundance $N_{1, t+1}=\frac{N_{0, t} W_{0, t}}{W_{1, t+1}^{q / r}}(5)$.

Recruitment variability is known to be partly due to environmental perturbations affecting early life history stages (Rothschild, 1986; Cushing, 1996; Chambers and Trippel, 1997). Here it is assumed that environmental fluctuations influence recruit number by determining recruit weight $W_{1, t}$ according to a normal distribution: $W_{1, t} \sim N\left(\mu_{W_{1}}, \sigma_{W_{1}}\right)(6)$. As a consequence, recruitment $N_{1, t+1}$ is determined by the weight and number of larvae, which result from past year events, and by $W_{1, t+1}$ which is constrained by random environmental fluctuations. 


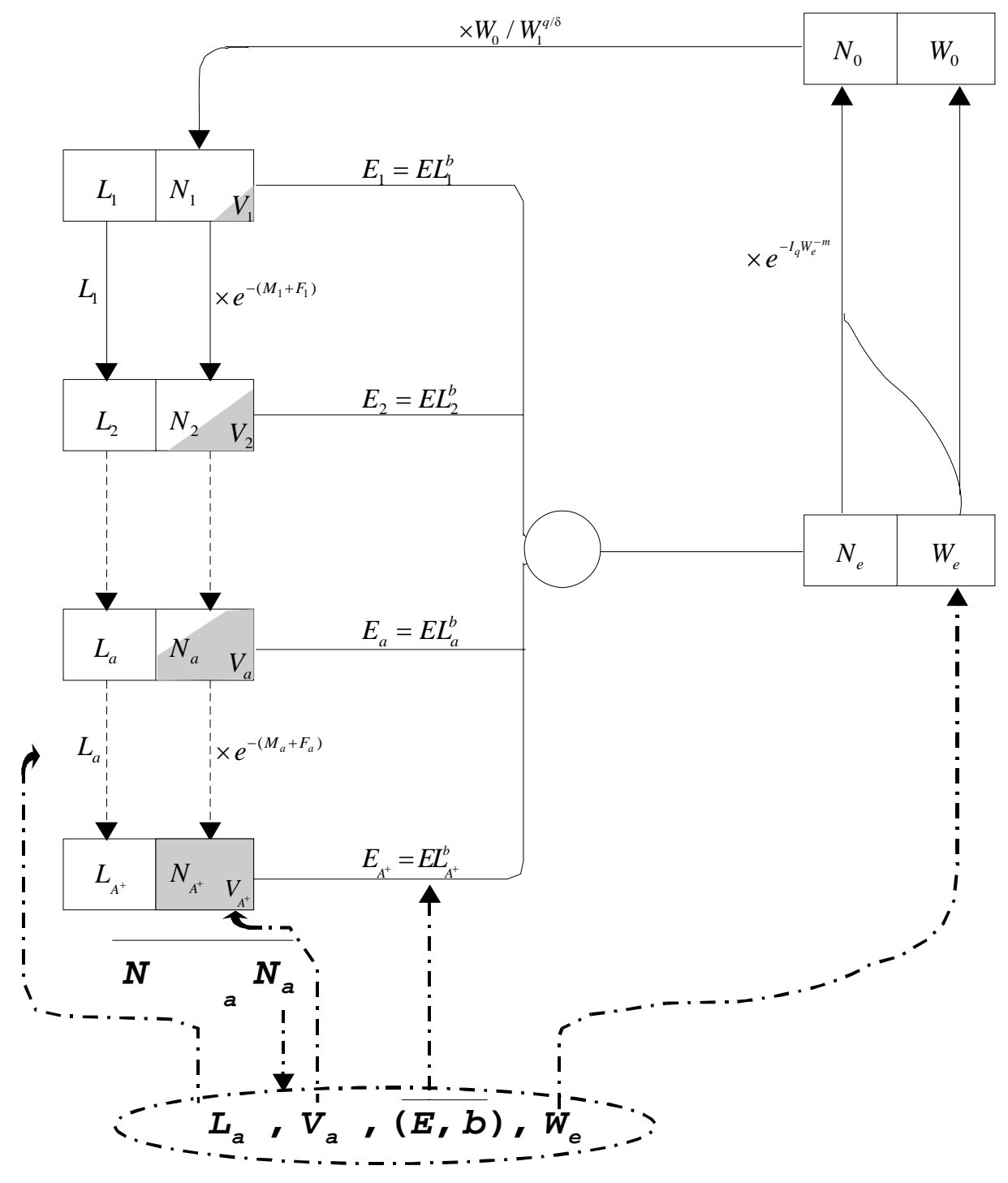

Figure 1. Flow diagram of the population model. Numbers at age $N_{a}$ survive from $N_{a-1}$ through fishing and natural mortality $F_{a}$ and $M_{a}$. The proportion mature $V_{a}$ of them reproduce with fecundity $E_{a}=E L_{a}^{b}$, where $L_{a}$ is length at age $a\left(L_{a, t}=L_{a-1, t-1}+\Delta L_{a-1}\right)$. The population produces $N_{e}$ eggs (weight $W_{e}$ ) which hatch into $N_{0}$ larvae (weight $W_{0}$ ) which in turn develop into $N_{1}$ recruits (weight $W_{1}$ determined by environmental variation). Density-dependence is implemented by assuming that the total population size $N$ determines the parameters $V, \Delta L, E, b$ and $W_{e}$. 


\section{2) Population parameters}

All adult stage parameters are estimated from observed values. Three typical Teleost populations with different strategies were chosen to illustrate the effect of density-dependence on BRP's. Their length- and weight-at-age, natural and fishing mortality (eqn 1), mean recruit number and the mean and variance of recruit weight (eqn 6) were taken from reports of ICES Stock Assessment Working Groups. Fecundity-length relationships (eqn 2) and egg size were obtained from the literature. North Sea cod was chosen as a typical Gadoid with large size and fast and indeterminate growth, and a slow increase of fecundity with size (Data from Daan, 1974; Oosthuizen and Daan, 1974; Hislop and Bell, 1987; Anonymous, 1998b; Markovic et al., 1998). Sardine in the Southern Area (VIIIc - IXa fishing areas) is a typical Clupeiforme with small size and more determinate growth (Data from Perez et al., 1985; Perez et al., 1992a; Perez et al., 1992b; Anonymous, 1999b). Sole in the Bay of Biscay has an intermediate strategy, with a less fluctuating recruitment (Data from Arbault and Boutin, 1968; Anonymous, 1992; Anonymous, 1998c). Lengths were converted into weights and the reverse using length-weight relationships $W_{a, t}=\alpha L_{a, t}^{\beta}$ found in Dorel (1986). All parameters definitions and values are summarised in the Appendix.

Reasonable guesses of early life parameters (eqns 4 and 5) are provided by Ware (1975) and Beyer (1989). Field values were gathered by Lorenzen (1996) and measured by Pepin (1991; 1993). Although the latter author does not assume a priori that growth and mortality have the same allometric coefficients, his estimates do not differ significantly, and hence can be used for the present simpler model. These parameters were not measured for the stocks considered, but body size may be a more important factor for larval characteristics than species-specific differences (Miller et al., 1992). Therefore various combinations of published early life parameters were used for any stock.

\section{3) Modelling density-dependence}

Compensatory effects were estimated by the fishing effects obtained from a previous comparative study (Rochet et al., Submitted, Table 1). In this study, the populations compared were contrasted on the basis of three types of environments with low (1), moderate (2) and high (3) fishing pressure. To incorporate these estimates, density-dependence is described here in a discrete way: the population parameters change with the total abundance of the stock $N_{t}=\sum_{a} N_{a, t}$. Thresholds $\tilde{N}_{1}$ and $\tilde{N}_{2}$ 
determine to which abundance level $g_{t} \in[1,2,3]$ year $t$ belongs : $N_{t} \leq \tilde{N}_{1} \Rightarrow g_{t}=3$; $\tilde{N}_{1}<N_{t} \leq \tilde{N}_{2} \Rightarrow g_{t}=2 ; \quad N_{t} \geq \tilde{N}_{2} \Rightarrow g_{t}=1 . g_{t}$ determines the parameters $A_{m}, \sigma_{A_{m}}, \Delta L, E, b$ and $W_{e}$ of eqns 1 to 3 .

Density-dependent effects were applied in two ways: $g_{t}$ determines the population parameters either for the whole population in year $t$ (year-effect), or for the cohort born in year $t$ (cohort-effect; in this case the model keeps track of the reproduction parameters during the whole life of the cohort). On the one hand, given a limited amount of resources, present abundance may affect the share of these resources available for each individual. There is field and experimental evidence that this in turn may affect their condition, fecundity and egg size (Hay and Brett, 1988; Kjesbu et al., 1991; Reznick, 1993; Marshall et al., 1998). This will result in year-effects of abundance on reproduction. On the other hand, the conditions encountered by a recruit during its early life may influence its characteristics during its subsequent life, e.g. its size at age (Rijnsdorp, 1993; Chambers and Leggett, 1996), maturation (Rijnsdorp, 1993; Hutchings, 1997) and mortality (Chambers, 1997). This is known as cohort effect.

Table 1. Relative effect of fishing: coefficients of change in demographic traits under increasing fishing pressure. Relative effect of moderate fishing $\delta_{2}$ : from low $(\mathrm{F} / \mathrm{M}<1)$ to moderate $(1 \leq \mathrm{F} / \mathrm{M}<2)$ fishing pressure; $\delta_{3}$ : from low to high $(\mathrm{F} / \mathrm{M} \geq 2)$ fishing pressure. For $b$, the relative effect of fishing is additive.

$A_{m}$ : median age at maturity; $L_{r m}$ : median length at maturity, relative to adult length; $E_{m}$ : fecundity at the median age at maturity; Egg: mean egg volume; $b$ : slope of the log-log fecundity-length relationship.

\begin{tabular}{lcc}
\hline & Relative effect of moderate fishing & \multicolumn{2}{c}{ Relative effect of high fishing } \\
& $\boldsymbol{\delta}_{\mathbf{2}}$ & $\boldsymbol{\delta}_{3}$ \\
\hline$A_{m}$ & 0.94 & 0.77 \\
$\boldsymbol{L}_{r m}$ & 1.05 & 1.09 \\
$\boldsymbol{E}_{m}$ & 0.25 & 0.26 \\
$E_{g g}$ & 0.73 & 0.63 \\
\hline $\boldsymbol{b}$ & 0.14 & 0.49 \\
\hline
\end{tabular}


The estimates from the comparative study are used here as follows: the three stocks simulated are presently under high fishing pressure. Their current age at maturity, fecundity-length parameters and length-at-age were used for low abundance levels $(g=3)$. The corresponding traits for higher abundance levels were derived by applying the coefficients in Table 1 as follows: $X_{g}=\delta_{g} X_{1}, \quad g=2,3, \quad X \in\left\{A_{m}, E_{m}, E g g, L_{r m}\right\}$ and $b_{g}=b_{1}+\delta_{g}, \quad g=2,3$ where $E_{m}$ is fecundity at median age at maturity, Egg is egg volume (converted to egg weight $W_{e}$, assuming they have the density of sea water) and $L_{r m}$ is length at maturity relative to adult length. The values for the parameter $E$ of the fecundity-length relationship (eqn 2) were obtained by $E_{g}=E_{m, g} / L_{A m, g}^{b_{g}}, \quad g=1,2,3$. Because it is difficult to find growth indices comparable between different species, no direct estimate of density-dependent effects on growth was available from the comparative study. However, growth is known to be highly density-dependent in many fish species (e.g. Beverton and Holt, 1957; Iles, 1971; Burd, 1984; Ross and Almeida, 1986; Overholtz, 1989; Kawasaki and Omori, 1995; Millner and Whiting, 1996; Rijnsdorp and van Leeuwen, 1996; Helser and Almeida, 1997; Tanasichuk, 1997; Shin and Rochet, 1998). Therefore the effects of fishing on the parameters of the von Bertalanffy growth model were tuned to mimic the effects of fishing on relative length at maturity $L_{r m}$. As these estimates of a compensatory response in growth are indirect, simulations were performed both including them and ignoring them (i.e., keeping growth fixed at its currently observed value across all abundance levels).

Some compensatory responses differ among life history strategies (Rochet et al., Submitted): whereas the effects on age at maturity, egg size and slope of the fecundity-length relationship are consistent among the taxonomic orders analysed, the response in fecundity at maturity differs among orders. Most fish taxa respond to fishing by increasing their fecundity at maturity, but in Clupeiformes fecundity at maturity is decreased by increasing fishing pressure. Therefore I used the mean estimate of fishing effect on $E_{m}$ for cod and sole, and no fishing effect on $E_{m}$ for sardine.

To estimate the thresholds $\tilde{N}_{1}$ and $\tilde{N}_{2}$ where the population parameters change, an equilibrium analysis was performed by using the classical dynamic pool equations (Thompson and Bell, 1934; Beverton and Holt, 1957) modified to estimate spawning biomass per recruit for each fishing mortality factor under a given exploitation pattern (Sissenwine and Shepherd, 1987; Gabriel et al., 
1989). This analysis was performed with the maturity ogive changing with fishing intensity, i.e. as the ratio $\mathrm{F} / \mathrm{M}$ decreases through the threshold values 1 and 2 (which was the criterion used in the comparative analysis to separate the groups of fishing pressure). $\tilde{N}_{1}$ and $\tilde{N}_{2}$ are the equilibrium population sizes at these thresholds.

\section{4) Simulating the model and performing sensitivity analysis}

Using the above equations, populations were simulated for 100 years. The 20 first simulated years were discarded to devoid results from the influence of initial conditions. Combinations of early-life parameters from within the range of published estimates (appendix B) were tuned to ensure that recruitment and spawning stock biomass during simulations under current fishing mortality remain within the observed window. In addition to these stock-recruitment plots, SSB of cohorts were plotted as a function of numbers recruited, to check the assumption that these two quantities are proportional. Fishing mortality factors were varied from 0 to 2 for cod and sole, and to 3 for sardine, by steps of 0.1 , to compute current spawning per recruit CSPR and the following reference points: $\mathrm{F}_{\text {low }}, \mathrm{F}_{\text {med }}, \mathrm{F}_{\text {high }}, \mathrm{F}_{30 \%}$ (cod and sole) or $\mathrm{F}_{35 \%}$ (sardine), and virgin spawning per recruit VSPR.

Sensitivity analysis of the population dynamics to early life stages parameters was performed by varying each of these parameters until the first value for which population grows exponentially (mean index of abundance level $g_{t}$ during a 100-year simulation, $\bar{g}=1$ ) or declines to extinction $(\bar{g}=3)$, all other parameters being fixed. Sensitivity of biological reference points to early life stages parameters was analysed by computing BRP's for various sets of these parameters.

Sensitivity of the BRP's to the various hypotheses of the model was also performed with various sets of early life parameters, always keeping simulated recruitment and SSB within the observed window: year effects versus cohort effects, fixed growth versus density-dependent growth, fixed size at recruitment versus size at recruitment varying under environmental influence.

\section{Results}

\section{1) Population dynamics}

In the absence of environmental variability, changes in population parameters by density-dependent effects generate cycles in population numbers (Fig. 2A). To obtain more realistic stock-recruitment 
plots and account for the interaction between recruitment variability and density dependence, subsequent simulations included environmental variations. Randomly varying size at recruitment $W_{1}$ within its observed range lets simulated recruitment and SSB vary within the observed window (Fig. 3), especially if density-dependent growth is taken into account. However, the spread of simulated recruitments does not span the range of observed recruitments at any SSB, suggesting that the model may underestimate environmental variability (Fig. 3).
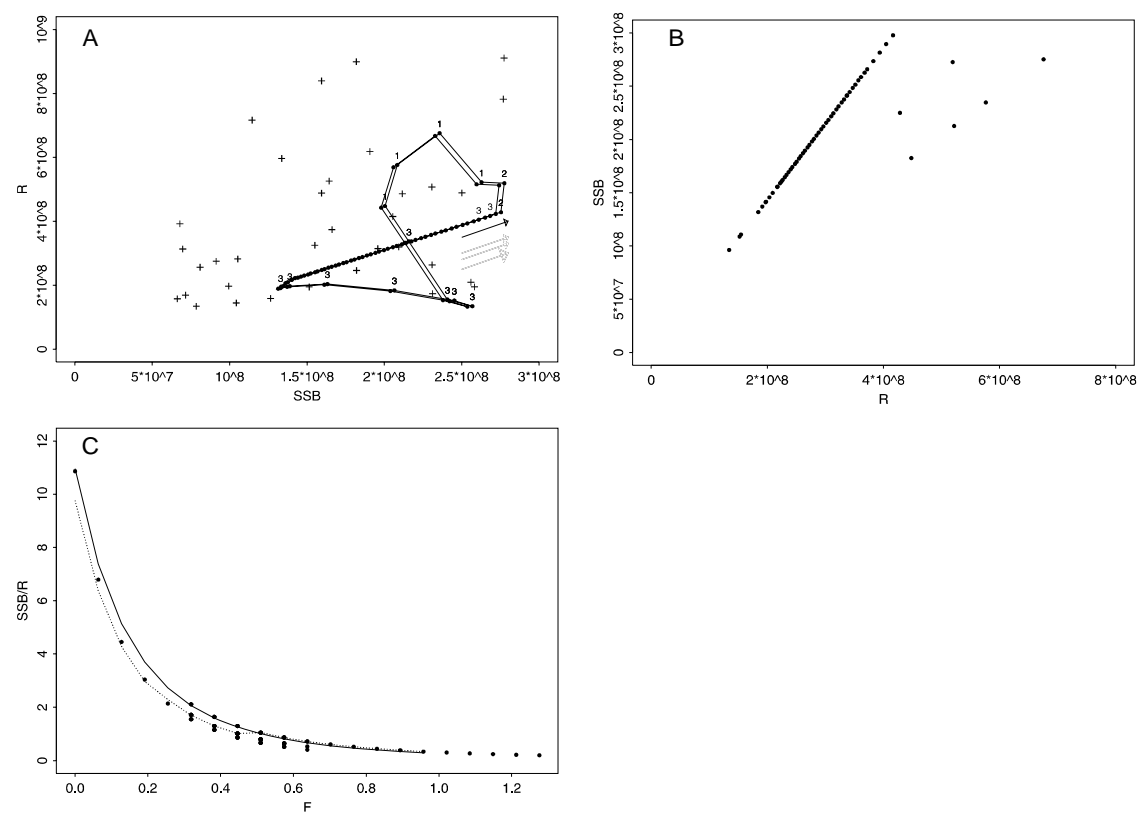

Figure 2. Simulations of the North sea cod population dynamics with a self regenerating model, with density-dependent reproduction, fixed growth, cohort effect and no environmental variability. $I=20, m=0.25, r=0.07, q=0.055, p=0.38$.

A) Stock-recruitment plot $\left(N_{1, t+1}\right.$ versus $\left.\operatorname{SSB}_{t}=\sum_{a=1}^{A^{+}} N_{a, t} V_{a, t} W_{a, t}\right)$ for a simulation under current fishing pressure $(\mathrm{F}=0.638)$. VPA-estimates $(+)$ and simulated points $(\bullet)$. Numbers refer to the abundance level of the corresponding year, arrow shows the direction of the population cycles.

B) Plot of cohort spawning stock biomass $\left(\sum_{i=1}^{A^{+}} N_{i, t+i-1} V_{i, t+i-1} W_{i, t+i-1}\right)$ versus number recruited $\left(N_{1, t}\right)$.

C) Spawning per recruit plots: classical equilibrium analysis (solid line), equilibrium analysis with maturity ogive changing with fishing mortality (dashed line), simulated self-regenerating model (dots). 

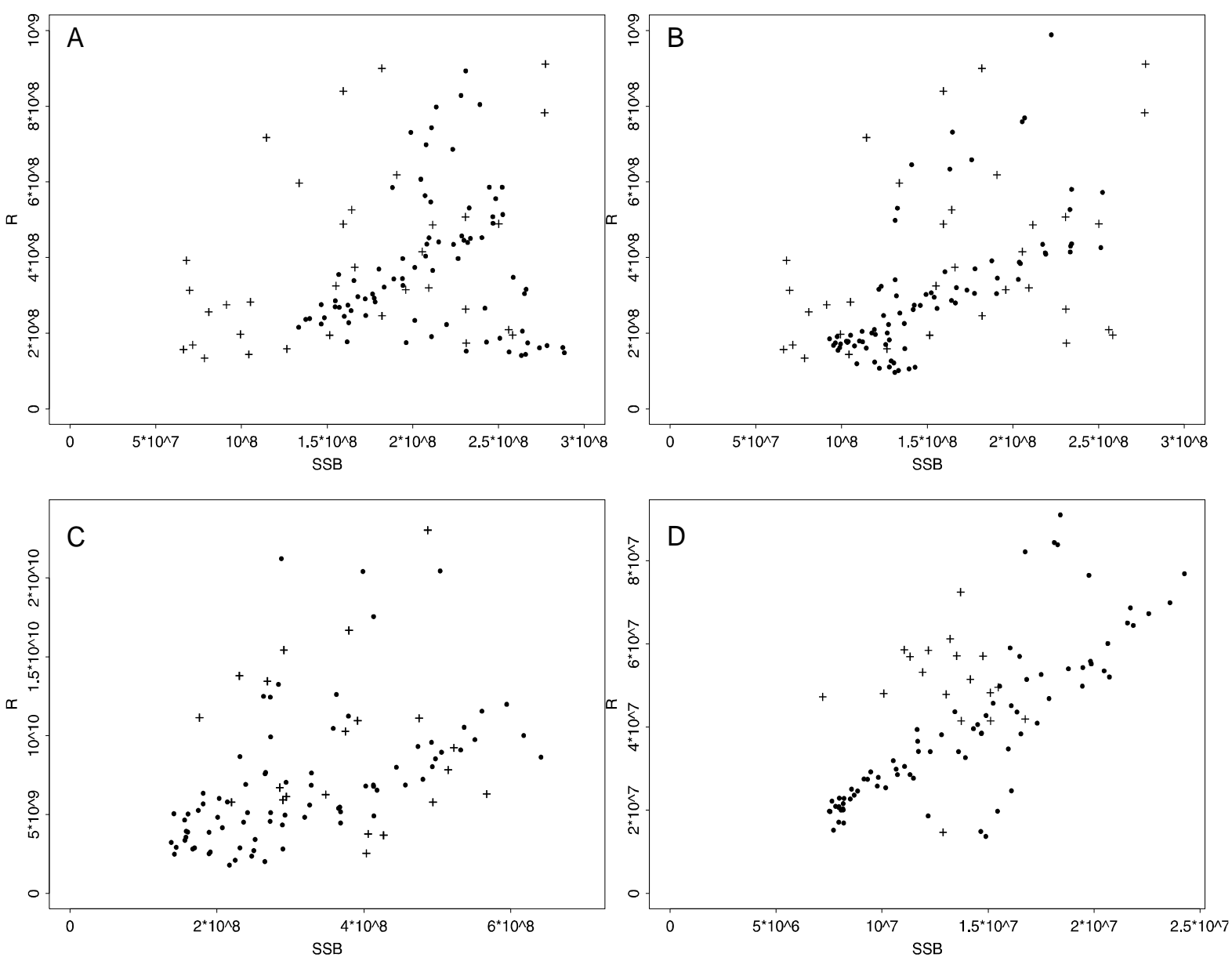

Figure 3. VPA-estimates $(+)$ and simulated $(\bullet)$ stock-recruitment plots under current fishing pressure, including environmental variability.

A) North Sea cod: $I=20, m=0.25, r=0.07, q=0.055, p=0.38$, cohort effect, fixed growth.

B) North Sea cod, same parameters, cohort effect, density-dependent growth.

C) Sardine in the Southern Area: $I=6, m=0.25, r=0.23, q=0.25, p=0.7$, cohort effect, fixed growth.

D) Bay of Biscay sole: $I=9, m=0.2, r=0.2, q=0.21, p=0.38$, cohort effect, density-dependent growth.

Population dynamics is most sensitive to $q$, the mortality rate of unit weight, and to $r$, the growth rate of unit weight (table 2). When juvenile mortality becomes too high relative to growth, recruitment is insufficient, and although the population remains in the low abundance level with high reproductive rates, it is driven to extinction. On the other hand, when mortality is low relative to growth, recruited numbers are very large and the population grows exponentially despite the lower reproductive rates associated with high abundances. This can seem unreasonable as regulation mechanisms may be enhanced when conditions get more extreme, but on the other hand there must be some limit to these 
regulation mechanisms. Unfortunately data collected in extreme conditions are seldom available. Therefore density-dependence effects were deliberately described as discrete and not approximated by a continuous function, to avoid unjustified assumptions outside the observed range of fishing pressures. The duration of the egg incubation period $I$, the ratio of larval to egg weight $p$, and the exponent $m$ of weight in growth and mortality rates are less sensitive parameters (table 2). A given change in $m$ will result in opposite effects on growth and mortality, explaining why results are the least sensitive to this parameter.

Table 2. Minimum changes in early life parameters necessary to lead to exponential population growth $(\bar{g}=1)$ or to population extinction $(\bar{g}=3)$ under current exploitation for North Sea cod, simulated with the self-regenerating model with density-dependent reproduction, fixed growth, and randomly varying recruit size.

$\bar{g}$ : mean abundance level index during a 100 year simulation. See appendix for definition of the parameters.

\begin{tabular}{lcccccc}
\hline Parameter & $\bar{g}$ & $\boldsymbol{I}$ & $\boldsymbol{m}$ & $\boldsymbol{r}$ & $\boldsymbol{q}$ & $\boldsymbol{p}$ \\
\hline Fixed value & 2.2875 & 20 & 0.2 & 0.232 & 0.15 & 0.38 \\
\hline Changes to exponential growth & 1 & $-41 \%$ & $+550 \%$ & $+15 \%$ & $-10 \%$ & $+500 \%$ \\
Changes to population extinction & 3 & $+14 \%$ & $-2200 \%$ & $-5 \%$ & $+4 \%$ & $-50 \%$ \\
\hline
\end{tabular}

\section{2) Replacement lines}

Under classical assumptions, for a given fishing mortality, any recruited cohort will produce a proportional spawning stock biomass. This is why a spawning biomass per recruit and the corresponding replacement line can be computed. But when density-dependent effects in adult population dynamics are taken into account, spawning stock biomass is no longer proportional to recruitment: spawning stock biomass increases less steeply when recruited numbers are high, if 
density-dependent effects are cohort effects (Fig. 2B and 4A). In the case of year effects, the proportionality is statistically true but perturbed by the variability in weight at age (Fig. 4B). This casts doubts about the concept of spawning biomass per recruit, and also of replacement lines of which the slope is the inverse of SPR. This is true for all three populations simulated (Fig. 4C and D). The departure from proportionality is the most important for cod, because i) cod has the oldest age at maturity, therefore a proportional change will have a greater impact on cod than on species with a younger age at maturity; ii) cod has the lowest slope of the fecundity-length relationship $b$, hence an additive change will have a greater impact on cod than on species with higher $b$; iii) in addition, for sardine there is no effect of abundance on fecundity at unit length $E$.
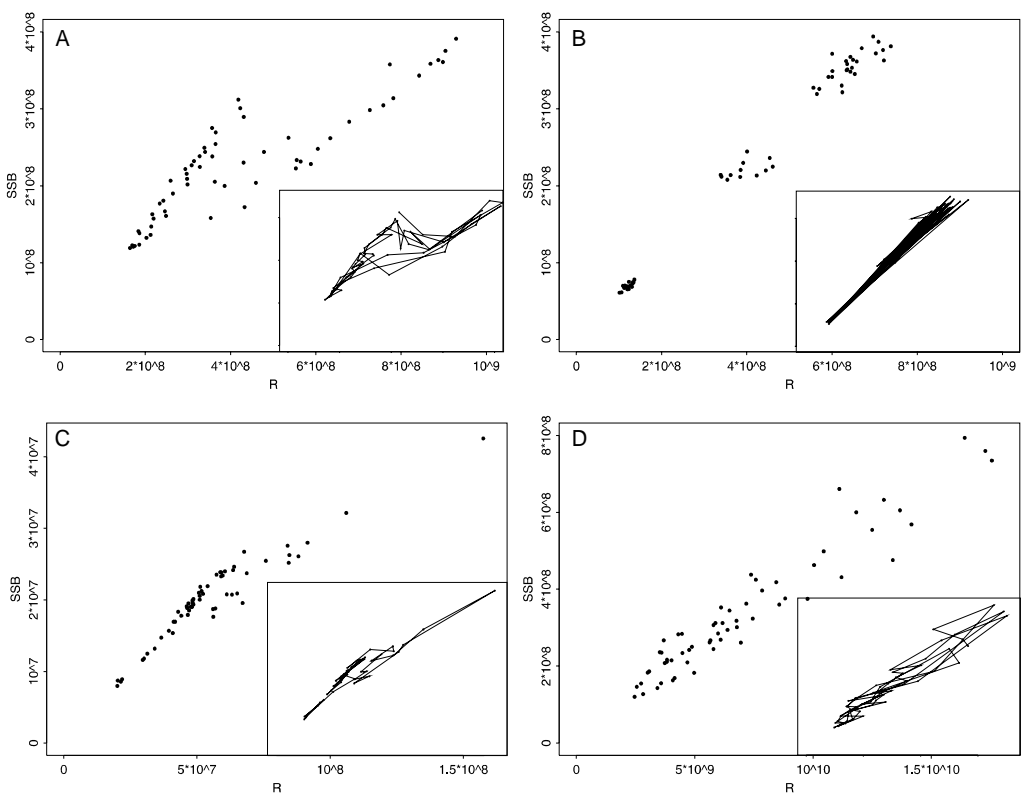

Figure 4. Simulated spawning stock biomass of successive cohorts $\left(\sum_{i=1}^{A^{+}} N_{i, t+i-1} V_{i, t+i-1} W_{i, t+i-1}\right)$ versus corresponding number recruited $\left(N_{1, t}\right)$, applying current fishing pressure (100 year simulations), fixed growth, varying recruit size. Inlays show the population dynamics by linking successive cohorts.
A) North Sea cod: $I=20, m=0.2, r=0.232, q=0.15, p=0.38$, cohort effect.
B) North Sea cod, same parameters, year effect.
C) Bay of Biscay sole: $I=9, m=0.2, r=0.2, q=0.21, p=0.38$, cohort effect.
D) Sardine in the Southern Area: $I=6, m=0.25, r=0.23, q=0.25, p=0.7$, cohort effect. 


\section{3) Biological Reference Points}

If it is not possible to compute unambiguous spawning biomass per recruit, then it will be difficult to estimate SPR-based biological reference points. One way of avoiding this difficulty is to consider density-dependence as uncertainty or biological variability, and to compute one SPR for each simulated cohort. Then a range of SPR rather than a single value can be associated with any given fishing mortality (Fig. 2C and 5). Changes in the maturity ogive with varying fishing pressure lead to lower expected gains of decreasing fishing mortality for cod, but the difference is small for sole and sardine. Changes in all reproductive parameters with abundance in the self-regenerating model lead to variability in SPR for the range of fishing mortality rates associated with population cycles (Fig. 2C). When environmental variability is introduced into the model, the range of such F's is increased (cohort effects: Fig. 5A) and there is additional variability in SPR due to the subsequent variability in weight at age (cohort effects and year effects: Fig. 5A \& B). The range of SPR's is larger for sardine because of the higher variability in recruit weight $W_{1}$, reflected in a higher variability of weight at any age.
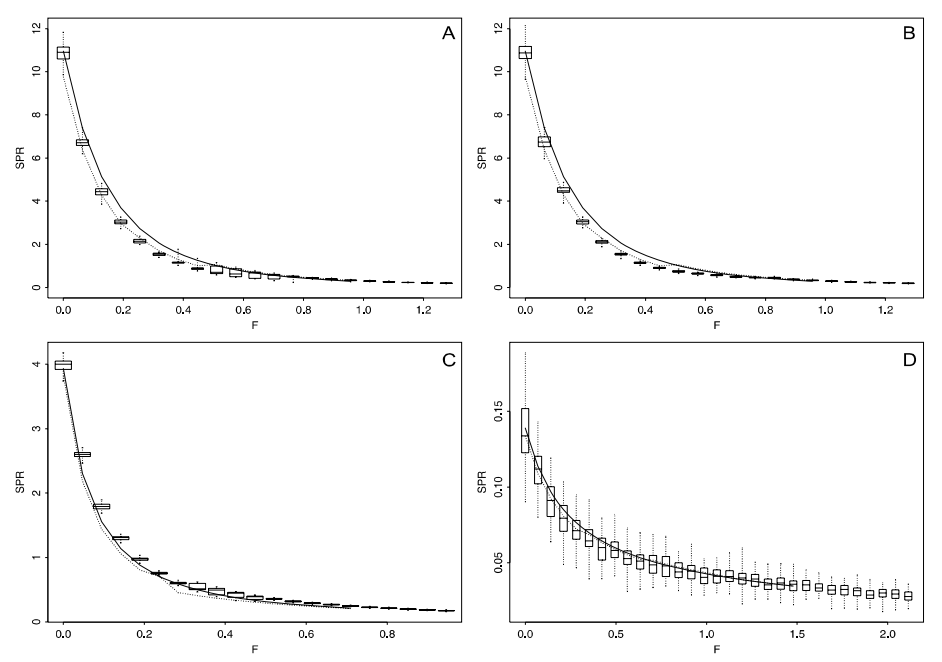

Figure 5. Spawning per recruit plots: classical equilibrium analysis (solid lines), equilibrium analysis with maturity ogives changing with fishing mortality (dashed lines), and the distribution of the simulated self-regenerating model with fixed growth and varying recruit size (boxes: quartiles, whiskers: extremes).

A) North Sea cod: $I=20, m=0.2, r=0.232, q=0.15, p=0.38$, cohort effect.

B) North Sea cod, same parameters, year effect.

C) Bay of Biscay sole: $I=9, m=0.2, r=0.2, q=0.21, p=0.38$, cohort effect.

D) Sardine in the Southern Area: $I=6, m=0.25, r=0.23, q=0.25, p=0.7$, cohort effect. 
From the minimum and maximum of all possible SPR's, extreme possible BRP's are computed (Fig. 6, table 3). When environmental variability is not taken into account and for high fishing mortality rates such as $\mathrm{F}_{\text {med }}$ and $\mathrm{F}_{\text {high, }}$ the simulated population remains in the low abundance level and there is a single SPR associated to these F's (Fig. 6). On the other hand, as soon as F decreases or environmental variability is introduced in the model, density-dependent effects introduce variability and/or bias compared to the classical density-independent estimates. Introduction of density-dependent growth yields a much lower estimate of VSPR compared to density-independent estimates, and a high uncertainty on all other BRP's. The ranges of these BRP's are wider when i) density effects are cohort effects than year effects ii) growth is density-dependent rather than fixed. Virgin spawning per recruit is largely overestimated by classical methods and is sensitive to density-dependence in any trait. $F_{\text {low, }}$ $F_{\text {med, }} F_{\text {high }}$ and current spawning per recruit have a large range of variation introduced by densitydependence consideration. By contrast, simulated $\mathrm{F}_{30 \%}$ seem robust to the parameters and hypotheses tested here, except density-dependent growth. This is because density-dependence is simulated in a discrete way in the present model: under low fishing mortality rates such as $\mathrm{F}_{30 \%}$, population abundance remains in the high level and the population parameters never change. For sardine the dependence of $\mathrm{F}_{35 \%}$ on biomass makes this BRP sensitive to the high size variability simulated for this stock. The estimated BRP's are not very sensitive to the parameters used for the early life stages. 

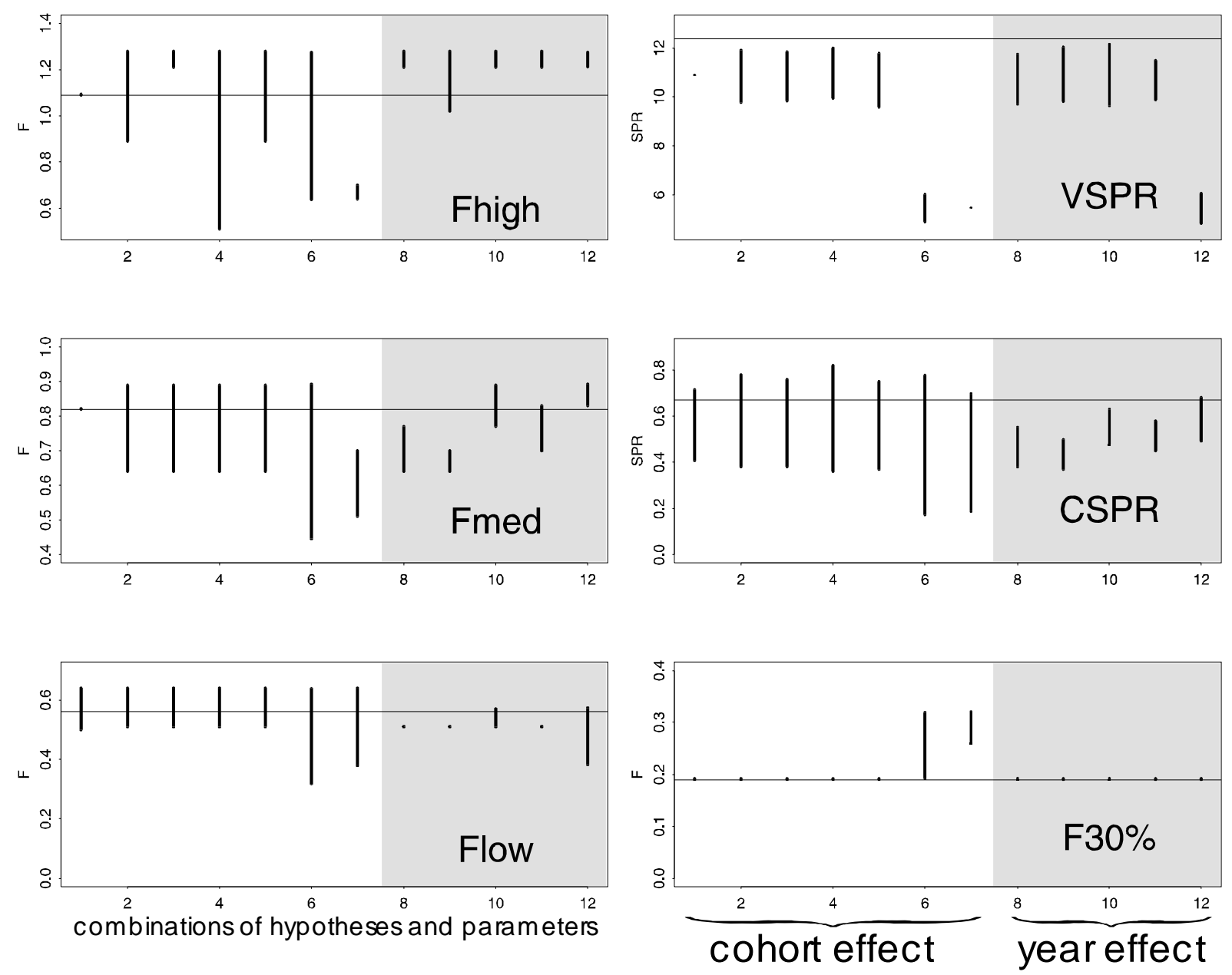

Figure 6. Ranges of Biological Reference Points for North Sea Cod estimated under various sets of hypotheses or early life stages parameters.

Thin horizontal line: classical density-independent equilibrium analysis (current $\mathrm{F}=0.638$ ).

\begin{tabular}{lcccccccc}
\hline Index & Env. Var. & $\begin{array}{c}\text { Density-dep } \\
\text { growth }\end{array}$ & $\begin{array}{c}\text { Year/cohort } \\
\text { effect }\end{array}$ & $\boldsymbol{I}$ & $\boldsymbol{m}$ & $\boldsymbol{r}$ & $\boldsymbol{q}$ & $\boldsymbol{p}$ \\
\hline 1 & No & No & cohort & 20 & 0.25 & 0.07 & 0.056 & 0.38 \\
2 & Yes & No & cohort & 20 & 0.25 & 0.25 & 0.15 & 0.38 \\
3 & Yes & No & cohort & 20 & 0.25 & 0.07 & 0.056 & 0.38 \\
4 & Yes & No & cohort & 20 & 0.2 & 0.232 & 0.15 & 0.38 \\
5 & Yes & No & cohort & 20 & 0.11 & 0.22 & 0.14 & 0.38 \\
6 & Yes & Yes & cohort & 20 & 0.25 & 0.07 & 0.056 & 0.38 \\
7 & No & Yes & cohort & 20 & 0.25 & 0.07 & 0.056 & 0.38 \\
\hline 8 & Yes & No & year & 20 & 0.25 & 0.25 & 0.15 & 0.38 \\
9 & Yes & No & year & 20 & 0.25 & 0.07 & 0.056 & 0.38 \\
10 & Yes & No & year & 20 & 0.2 & 0.232 & 0.15 & 0.38 \\
11 & Yes & No & year & 20 & 0.11 & 0.22 & 0.14 & 0.38 \\
12 & Yes & Yes & year & 20 & 0.25 & 0.07 & 0.056 & 0.38 \\
\hline
\end{tabular}


Table 3. Biological Reference Points for Bay of Biscay sole and sardine in the southern Area, as estimated by classical SPR methods, and range from the self-regenerating model with densitydependent reproduction, fixed growth, and randomly varying recruit size. VSPR, virgin spawning biomass per recruit. CSPR, current SPR.

$\bar{g}$ : mean abundance level index during a 100 year simulation, under current exploitation.

$\left.{ }^{*}\right)$ For sardine, in all simulations $F_{\text {high }}>2.1$, the largest F-value used in simulations.

\begin{tabular}{|c|c|c|c|c|c|c|c|c|c|c|c|}
\hline \multicolumn{5}{|c|}{ Early life stages parameters } & \multicolumn{2}{|l|}{$\bar{g}$} & \multicolumn{4}{|c|}{ Biological Reference Points } & \multirow[b]{2}{*}{ CSPR } \\
\hline $\boldsymbol{I}$ & $m$ & $r$ & $q$ & $p$ & $\bar{g}$ & $F_{\text {low }}$ & $F_{\text {med }}$ & Fhigh & $\mathbf{F}_{30 \%}$ & VSPR & \\
\hline \multicolumn{12}{|c|}{ Bay of Biscay sole, classical equilibrium analysis $\left(\mathrm{F}_{\mathrm{ref}}=0.4729\right)$} \\
\hline & & & & & & 0.42 & 0.56 & 0.71 & 0.14 & 3.94 & 0.34 \\
\hline \multicolumn{12}{|c|}{ Bay of Biscay sole, self-regenerating model, cohort effect } \\
\hline 9 & 0.2 & 0.2 & 0.21 & 0.38 & 2.713 & $0.43-0.47$ & $0.61-0.66$ & $0.76-0.85$ & 0.14 & $3.74-4.18$ & $0.32-0.42$ \\
\hline 14 & 0.25 & 0.07 & 0.08 & 0.38 & 2.675 & $0.43-0.47$ & $0.61-0.66$ & $0.80-0.85$ & 0.14 & $3.68-4.16$ & $0.29-0.42$ \\
\hline \multirow[t]{2}{*}{14} & 0.25 & 0.21 & 0.2 & 0.38 & 2.475 & $0.43-0.47$ & $0.61-0.66$ & $0.76-0.80$ & 0.14 & $3.80-4.20$ & $0.28-0.42$ \\
\hline & & & & & & $F_{\text {low }}$ & $F_{\text {med }}$ & $\mathbf{F}_{35 \%}$ & $F_{\text {high }}$ & VSPR & CSPR \\
\hline \multicolumn{12}{|c|}{ Sardine in the southern Area, classical equilibrium analysis $\left(\mathrm{F}_{\mathrm{ref}}=0.7044\right)$} \\
\hline & & & & & & 0.07 & 0.75 & 0.64 & 2.54 & 0.13 & 0.05 \\
\hline \multicolumn{12}{|c|}{ Sardine in the southern Area, self-regenerating model, cohort effect } \\
\hline 6 & 0.25 & 0.07 & 0.082 & 0.7 & 1.838 & $0-0.07$ & $0.35-1.55$ & $0.7-1.06$ & $\left({ }^{*}\right)$ & $0.10-0.17$ & $0.03-0.06$ \\
\hline 6 & 0.11 & 0.2 & 0.22 & & 2.188 & $0-0.07$ & $0.42-1.69$ & $0.85-0.85$ & $\left({ }^{*}\right)$ & $0.09-0.17$ & $0.03-0.07$ \\
\hline 6 & 0.25 & 0.23 & 0.25 & 0.7 & 1.888 & $0-0.07$ & $0.21-1.41$ & $0.56-0.77$ & $\left({ }^{*}\right)$ & $0.09-0.19$ & $0.03-0.07$ \\
\hline
\end{tabular}




\section{Discussion}

Spawning per recruit is an ambiguous concept if populations are regulated in a density-dependent way during the adult stage. The spawning biomass developed by an average recruit depends on the number recruited, which varies under the combined influences of the recent history of the population and of environmental fluctuations. Although my figures of spawning stock biomass against recruitment (Fig. 4) look unrealistic because of the discreteness of the estimated effects, they undoubtedly show that these quantities are not proportional, as it would be required to compute spawning per recruit.

The quantitative and practical consequences of this flaw are not negligible. Both density-dependence in growth and reproduction contribute to the non-proportionality of spawning biomass to recruitment, but the quantitative consequences of density-dependence in growth are higher because individual weight is the building stone for SSB. These findings are qualitatively in agreement with previous single-stock studies (Overholtz et al., 1991; Patterson, 1997; Helser and Brodziak, 1998). Predicted stock rebuilding might be overoptimistic when density dependence is neglected. Density dependent effects are expected to affect BRP's computations to a greater extent for large and longlived fish with a large proportion of growth after maturity (like cod).

These conclusions are orders of magnitude rather than precise estimates, because the model has been deliberately kept as simple as possible, with few parameters, all of which can be estimated, aiming to describe the most important effects of fishing on the life cycle. This choice has the following consequences. i) Only a subset of possible density-dependent processes have been investigated, neglecting for example changes in natural mortality. ii) Stochasticity is introduced in the model process only in the mean weight for recruits. This probably underestimates the influence of environmental variability. For sardine, which has the largest variance in recruit weight, the overlap between the simulated and observed spread in the stock-recruit plot is better than for cod and sole, and the resulting variability in BRP's is high. iii) It was assumed that density-dependent effects can be estimated by fishing effects. Clearly, the novel environment created by fishing may induce both phenotypic responses and evolutionary changes (Stokes et al., 1993), which are confounded in the available estimates. However, plastic responses to food availability may be much larger than evolved responses to high and selective mortality rates (Reznick, 1993). iv) The estimates of density-dependent 
effects were obtained across many populations. This avoids confusion with effects of environmental influence, but results in estimates of mean effects on all these populations. As all species may not react equally to fishing, the present results improve our insight into the consequences of densitydependence on stock-assessments in general, rather than on any particular stock. v) Two possibilities were tested for the way abundance may affect the reproductive potential of the population: yeareffects and cohort-effects. Stock abundance probably acts in both manners on reproduction. It is not possible to decide which of the figures 4-5 A or B is closer to reality; reality is probably somewhere in between, or the sum of both effects. vi) The results are also influenced by the discrete structure of the model. For example, a continuous model would probably conclude that $\mathrm{F}_{30} \%$ is not robust to densityindependent assumptions, unlike the present model. The discreteness of the model was imposed by the choice of incorporating only observed effects in the model. BRP's such as VSPR or $\mathrm{F}_{30} \%$ rely on stock states for which we have few information because they have been seldom observed; hence there is a high uncertainty in their estimates, even if we are not able to quantify this uncertainty.

The uncertainty about density-dependent processes involved in stock dynamics comes in addition to the various sources of errors and uncertainty known to affect stock assessment and BRP's computations. It is of the same magnitude as variations in $\mathrm{F}_{\text {med }}$ predicted by Jakobsen (1992; 1993) in response to assumed variations in growth and maturity parameters. It is also of the same magnitude as the variability of $F_{\text {med }}$ and $F_{\text {crash }}$ due to observed recruitment variability, as estimated by bootstrap methods for Georges Bank cod (Murawski et al., 1998) and for North-East Arctic cod and haddock (Jakobsen, 1992). On the other hand, the variability of $F_{m s y}$ caused by observed variability in recruitment, weight, selectivity and maturity in Icelandic haddock, estimated by bootstrap methods, may be much larger (Anonymous, 1999a). From this short review it is concluded that densitydependence effects are of practical importance, although they are not the only concern over the precision of BRP's estimates. In addition, SPR computations are projections under a fixed exploitation diagram, whereas the real exploitation diagram is expected to vary. SPR and $\mathrm{F}_{\text {med }}$ estimates have been shown to be sensitive to such changes (Jakobsen, 1992; Jakobsen, 1993).

More basically, the present study casts doubts about the real meaning of these BRP's, because spawning per recruit is not a well-defined quantity. To avoid reasoning on a 'per recruit' basis would clarify diagnostics. The conceptual weakness of SPR is most preoccupying for BRP's defined directly 
from replacement lines, such as $F_{\text {low }}, F_{\text {med }}, F_{\text {high }}$ and $F_{\text {loss. }}$ Although the idea of dividing the stockrecruitment plot by replacement lines is appealing because it avoids assumptions about the spawnerrecruit function, it does not avoid any assumption on stock dynamics. BRP's including a stock recruitment relationship such as $\mathrm{F}_{\mathrm{msy}}$ or $\mathrm{F}_{\text {crash }}$ should be less sensitive to this problem because the stock recruitment relationship more or less explicitly includes density-dependent regulations.

In addition, SPR has other disadvantages. There is increasing concern that spawning biomass, considering only weight and proportion mature at age, is not a good index of reproductive potential. It may be improved by additional information such as effects of spawner age or size on fecundity (Leaman, 1986; Lambert, 1990; Katsukawa, 1997; Marshall et al., 1998; Marteinsdottir and Thorarinsson, 1998), and on egg size and egg and larval viability (MacKenzie et al., 1998; Murawski et al., 1998). Another possible improvement would be to monitor more than one or two quantities such as fishing mortality and stock biomass. It has been recommended to use several criteria to manage a fishery because objectives as well as technical criteria are multiple (Caddy and Mahon, 1996). But from a biological point of view, population indices and the associated BRP's are usually fishing mortality rates and/or biomasses, all defined and estimated from the same models and data (e.g. Caddy and Mahon, 1996; Deriso et al., 1998). There is a need to think about other indices of stock potential to be monitored together with these BRP's, such as the growth and condition of spawners (Marshall and Frank, 1999), their hepato-somatic index (Lambert and Dutil, 1997; Marshall et al., 1999), the growth rate of the population (Hutchings and Myers, 1994), life history traits (Rochet, In the press) or other new indices to be found.

\section{Acknowledgements}

I thank Olivier Le Pape, Olivier Maury, Benoit Mesnil, Pierre Pepin, Paul Starr and Verena Trenkel for helpful comments on previous versions of this paper.

\section{References}

Anonymous. 1991. Report of the Advisory Committee on Fishery Management for 1991. ICES Cooperative Research Report, 179.

Anonymous. 1992. Report of the Study Group on the fecundity of sole and plaice in sub areas IV, VII, and VIII. ICES C.M. 1992 / G: 16.

Anonymous. 1997. Report of the Comprehensive Fishery Evaluation Working Group. ICES CM 1997/Assess:15, $140 \mathrm{pp}$. 
Anonymous. 1998a. Report of the study group on the precautionary approach to fisheries management. ICES CM 1998/ACFM: 10 Ref. D, 40 pp.

Anonymous. 1998b. Report of the working group on the assessment of demersal stocks in the North Sea and Skagerrak. ICES C.M. 1998 / Assess: 7, 702 pp.

Anonymous. 1998c. Report of the working group on the assessment of Southern Shelf demersal stocks. ICES C.M. 1998 / Assess: 4, 664 pp.

Anonymous. 1999a. Report of the Comprehensive Fishery Evaluation Working Group. ICES CM 1999/D:1, 156 pp.

Anonymous. 1999b. Report of the working group on the assessment of mackerel, horse mackerel, sardine and anchovy. ICES CM 1999/ ACFM: 6, 468 pp.

Arbault, S., and Boutin, N. 1968. Ichthyoplancton. Eufs et larves de poissons téléostéens dans le Golfe de Gascogne en 1964. Revue des Travaux de l'Institut des Pêches maritimes, 32: 413-476.

Beverton, R. J. H., and Holt, S. J. 1957. On the dynamics of exploited fish populations. Fishery Investigations, Series II, 19, Her Majesty's Stationery Office, London. 533 pp.

Beyer, J. E. 1989. Recruitment stability and survival - simple size-specific theory with examples from the early life dynamics of marine fish. Dana, 7: 45-147.

Brooks, S., Tyler, C. R., and Sumpter, J. P. 1997. Egg quality in fish: what makes a good egg? Reviews in Fish Biology and Fisheries, 7: 387-416.

Burd, A. C. 1984. Density-dependent growth in North Sea herring. ICES CM/H: 4, 5 pp.

Caddy, J. F., and Mahon, R. 1996. Reference points for fisheries management. FAO Fisheries Technical Paper, 347, FAO, Rome. 83 pp.

Chambers, R. C. 1997. Environmental influences on egg and propagule sizes in marine fishes. In Early life history and recruitment in fish populations, pp 63-102. Ed. by R. C. Chambers and E. A. Trippel. Chapman and Hall, London. 596 pp.

Chambers, R. C., and Leggett, W. C. 1996. Maternal influences on variation in egg sizes in temperate marine fishes. American Zoologist, 36: 180-196.

Chambers, R. C., and Trippel, E. A., eds. 1997. Early life history and recruitment in fish populations. Fish and Fisheries Series, Chapman and Hall, London.

Cook, R. M. 1998. A sustainability criterion for the exploitation of North Sea cod. ICES Journal of marine Science, 55: 1061-1070.

Cushing, D. H. 1996. Towards a science of recruitment in fish populations. Excellence in Ecology, 7, Ecology Institute, Oldendorf/Luhe. 175 pp.

Daan, N. 1974. Growth of North Sea cod, Gadus morhua. Netherlands Journal of Sea Research, 8: 27-48.

Deriso, R., Quinn, T., Collie, J., Hilborn, R., Jones, C., Lindsay, B., Parma, A., Saila, S., Shapiro, L., Smith, S. J., and Walters, C. 1998. Improving fish stock assessments. National Academy Press, Washington. 177 pp.

Dorel, D. 1986. Poissons de l'Atlantique Nord-Est. Relations taille/poids. Rapport Interne, DRV-86001/RH/NANTES, 185 pp.

Gabriel, W. L., Sissenwine, M. P., and Overholtz, W. J. 1989. Analysis of spawning stock biomass per recruit: an example for Georges Bank haddock. North American Journal of Fisheries Management, 9: 383-391.

Hay, D. E., and Brett, J. R. 1988. Maturation and fecundity of pacific herring (Clupea harengus pallasi): an experimental study with comparisons to natural populations. Canadian Journal of Fisheries and Aquatic Sciences, 45: 399-406.

Helser, T. E., and Almeida, F. P. 1997. Density-dependent growth and sexual maturity of silver hake in the north-west Atlantic. Journal of Fish Biology, 51: 607-623. 
Helser, T. E., and Brodziak, J. K. T. 1998. Impacts of density-dependent growth and maturation on assessment advice to rebuild depleted U.S. silver hake (Merluccius bilinearis) stocks. Canadian Journal of Fisheries and Aquatic Sciences, 55: 882-892.

Hempel, G. 1978. North sea fisheries and fish stocks - a review of recent changes. Rapports et Procèsverbaux des Réunions du Conseil international pour l'Exploration de la Mer, 173: 145-167.

Hislop, J. R. G., and Bell, M. A. 1987. Observations on the size, dry weight and energy content of the eggs of some demersal fish species from British marine waters. Journal of Fish Biology, 31: 120.

Horwood, J. W., Bannister, R. C. A., and Howlett, G. J. 1986. Comparative fecundity of North Sea plaice (Pleuronectes platessa L.). Proceedings of the Royal Society of London B, Biological Sciences, 228: 401-431.

Houde, E. D. 1997. Patterns and trends in larval-stage growth and mortality of teleost fish. Journal of Fish Biology, 51 (Supplement A): 52-83.

Hutchings, J. A. 1997. Life history responses to environmental variability in early life. In Early life history and recruitment in fish populations, pp 139-168. Ed. by R. C. Chambers and E. A. Trippel. Fish and Fisheries Series, 21, Chapman and Hall, London. 596 pp.

Hutchings, J. A., and Myers, R. A. 1994. What can be learned from the collapse of a renewable resource? Atlantic cod, Gadus morhua, of Newfoundland and Labrador. Canadian Journal of Fisheries and Aquatic Sciences, 51: 2126-2146.

Iles, T. D. 1971. Growth studies on North Sea herring III. The growth of East Anglian herring during the adult stage of the life history for the years 1940 to 1967. Journal du Conseil international pour l'Exploration de la Mer, 33: 386-420.

Jakobsen, T. 1992. Biological reference points for North-East Arctic cod and haddock. ICES Journal of marine Science, 49: 155-166.

Jakobsen, T. 1993. The behaviour of Flow, Fmed and Fhigh in response to variation in parameters used for their estimation. Canadian Special Publication of Fisheries and Aquatic Sciences, 120: 119-125.

Katsukawa, T. 1997. Introduction of spawning potential: improvement in the threshold management theory. Reviews in Fish Biology and Fisheries, 7: 285-289.

Kawasaki, T., and Omori, M. 1995. Possible mechanisms underlying fluctuations in the Far Eastern sardine population inferred from time series of two biological traits. Fisheries Oceanography, 4: $238-242$.

Kjesbu, O., Klungsøyr, J., Kryvi, H., Witthnames, P. R., and Greer Walker, M. G. 1991. Fecundity, atresia, and egg size of captive Atlantic cod (Gadus morhua) in relation to proximate body composition. Canadian Journal of Fisheries and Aquatic Sciences, 48: 2333-2343.

Kjesbu, O. S., Solemdal, P., Bratland, P., and Fonn, M. 1996. Variation in annual egg production in individual captive Atlantic cod (Gadus morhua). Canadian Journal of Fisheries and Aquatic Sciences, 53: 610-620.

Kotilainen, P., and Aro, E. 1991. Changes in growth rate of Baltic herring and their causes in the Northern Baltic Sea. ICES C.M. 1991/J: 17, 22 pp.

Lambert, T. C. 1990. The effect of population structure on recruitment in herring. Journal du Conseil international pour l'Exploration de la Mer, 47: 249-255.

Lambert, Y., and Dutil, J.-D. 1997. Can simple condition indices be used to monitor and quantify seasonal changes in the energy reserves of Atlantic cod (Gadus morhua)? Canadian Journal of Fisheries and Aquatic Sciences, 54 (Suppl. 1): 104-112.

Leaman, B. M. 1986. Incorporating reproductive value into Pacific ocean perch management, pp 355368. International Rockfish Symposium, Anchorage, Alaska. 
Lorenzen, K. 1996. The relationship between body weight and natural mortality in juvenile and adult fish: a comparison of natural ecosystems and aquaculture. Journal of Fish Biology, 49: 627-647.

Mace, P. M., and Sissenwine, M. P. 1993. How much spawning per recruit is enough? Canadian Special Publication of Fisheries and Aquatic Sciences, 120: 101-118.

MacKenzie, B. R., Tomkiewicz, J., Köster, F., and Nissling, A. 1998. Quantifying and disaggregating the spawner effect: Incorporating stock structure, spatial distribution and female influences into estimates of annual population egg production. ICES CM 1998/BB: 11, 23.

Markovic, L., Rochet, M.-J., and Plantagenest, M. 1998. Factors of variation of age and size at maturity in some North Sea gadiformes, NAFO symposium 'Variations in Maturation, Growth, Condition and Spawning Stock Biomass Production in Groundfish', Lisbonne.

Marshall, C. T., and Frank, K. T. 1999. The effect of interannual variation in growth and condition on haddock recruitment. Canadian Journal of Fisheries and Aquatic Sciences, 56: 347-355.

Marshall, C. T., Kjesbu, O. S., Yaragina, N. A., Solemdal, P., and Ulltang, Ø. 1998. Is spawner biomass a sensitive measure of the reproductive and recruitment potential of Northeast Arctic cod? Canadian Journal of Fisheries and Aquatic Sciences, 55: 1766-1783.

Marshall, C. T., Yaragina, N. A., Lambert, Y., and Kjesbu, O. S. 1999. Total lipid energy as a proxy for total egg production by fish stocks. Nature, 402: 288-290.

Marteinsdottir, G., and Thorarinsson, K. 1998. Improving the stock-recruitment relationship in Icelandic cod (Gadus morhua L.) by including age diversity of spawners. Canadian Journal of Fisheries and Aquatic Sciences, 55: 1372-1377.

Miller, T. J., Crowder, L. B., Rice, J. A., and Binkowski, F. P. 1992. Body size and the ontogeny of the functional response in fishes. Canadian Journal of Fisheries and Aquatic Sciences, 49: 805-812.

Millner, R. S., and Whiting, C. L. 1996. Long-term changes in growth and population abundance of sole in the North Sea from 1940 to the present. ICES Journal of marine Science, 53: 1185-1195.

Murawski, S. A., Rago, P. J., and Trippel, E. A. 1998. Impacts of demographic variation in spawning success on reference points for fishery management, pp 77-85. 5th NMFS Stock Assessment Workshop, Key Largo, Florida. NOAA Tech. Memo. NMFS-F/SPO, 40.

Oosthuizen, E., and Daan, N. 1974. Egg fecundity and maturity of North Sea cod, Gadus morhua. Netherlands Journal of Sea Research, 8: 378-397.

Overholtz, W. J. 1989. Density-dependent growth in the Northwest Atlantic stock of Atlantic mackerel (Scomber scombrus). Journal of Northwest Atlantic Fishery Science, 9: 115-121.

Overholtz, W. J., Murawski, S. A., and Michaels, W. L. 1991. Impact of compensatory responses on assessment advice for the Northwest Atlantic mackerel stock. Fishery Bulletin, 89: 117-128.

Parmanne, R. 1992. Changes in the growth of herring in the Northern Baltic Sea in 1970-1991. ICES C.M. 1992/J: 42, 19 pp.

Patterson, K. R. 1997. Density-dependence of growth and maturity in the Norwegian spring-spawning herring, and implications for yield calculations. ICES CM 1997/DD:07, 11 pp.

Pepin, P. 1991. Effect of temperature and size on development, mortality, and survival rates of the pelagic early life history stages of marine fish. Canadian Journal of Fisheries and Aquatic Sciences, 48: 503-518.

Pepin, P. 1993. Application of empirical size-dependent models of larval fish vital rates to the study of production: accuracy and association with adult stock dynamics in a comparison among species. Canadian Journal of Fisheries and Aquatic Sciences, 50: 53-59.

Perez, N., Figueiredo, I., and Macewicz, B. J. 1992a. The spawning frequency of sardine, Sardina pilchardus (Walb.), off the Atlantic Iberian coast. Boletin del Instituto Espanol de Oceanografia, 8: 175-189.

Perez, N., Figueiredo, I., and N.C.H., L. 1992b. Batch fecundity of Sardina pilchardus (Walb.) off the Atlantic Iberian coast. Boletin del Instituto Espanol de Oceanografia, 8: 155-162. 
Perez, N., Porteiro, C., and Alvarez, F. 1985. Contribucion al conocimiento de la biologia de la sardina de Galicia. Boletin del Instituto Espanol de Oceanografia, 2: 27-37.

Pitt, T. K. 1975. Changes in abundance and certain biological characteristics of Grand Bank American Plaice, Hippoglossoides platessoides. Journal of the Fishery Research Board of Canada, 32: 13831398.

Reznick, D., Callahan, H., and Llauredo, R. 1996. Maternal effects on offspring quality in Poeciliid fishes. American Zoologist, 36: 147-156.

Reznick, D. N. 1993. Norms of reaction in fishes. In The exploitation of evolving resources, pp 72-90. Ed. by T. K. Stokes, J. M. McGlade, and R. Law. Lecture Notes in Biomathematics, 99, Springer-Verlag, Berlin.

Ricker, W. E. 1954. Stock and recruitment. Journal of the Fisheries Research Board of Canada, 11: 559623.

Rijnsdorp, A. D. 1993. Relationship between juvenile growth and the onset of sexual maturity of female North Sea plaice, Pleuronectes platessa. Canadian Journal of Fisheries and Aquatic Sciences, 50: 1617-1631.

Rijnsdorp, A. D. 1994. Population-regulating processes during the adult phase in flatfish. Netherlands Journal of Sea Research, 32: 207-223.

Rijnsdorp, A. D., Daan, N., van, B., F.A., and Heessen, H. J. L. 1991. Reproductive variability in North Sea plaice, sole, and cod. Journal du Conseil international pour l'Exploration de la Mer, 47: 352-375.

Rijnsdorp, A. D., and Jaworski, A. 1990. Size-selective mortality in plaice and cod eggs: a new method in the study of egg mortality. Journal du Conseil international pour l'Exploration de la Mer, 47: 256-263.

Rijnsdorp, A. D., and van Leeuwen, P. I. 1992. Density-dependent and independent changes in somatic growth of female North Sea plaice Pleuronectes platessa between 1930 and 1985 as revealed by back-calculation of otoliths. Marine Ecology Progress Series, 88: 19-32.

Rijnsdorp, A. D., and van Leeuwen, P. I. 1996. Changes in growth of North Sea plaice since 1950 in relation to density, eutrophication, beam-trawl effort, and temperature. ICES Journal of marine Science, 53: 1199-1213.

Rochet, M. J. 1998. Short term effects of fishing on life history traits of fishes. ICES Journal of marine Science, 55: 371-391.

Rochet, M. J. In the press. May life history traits be used as indices of population viability? Journal of Sea Research,

Rochet, M. J., Cornillon, P. A., Sabatier, R., and Pontier, D. Submitted. Impact of fishing on life history traits of marine Teleost fishes: A statistical model for discriminating between phylogenetic and environmental effects.

Ross, M. R., and Almeida, F. P. 1986. Density-dependent growth of Silver Hakes. Transactions of the American Fisheries Society, 115: 548-554.

Rothschild, B. J. 1986. Dynamics of marine fish populations. Harvard University Press, Cambridge, Massachussetts. 277 pp.

Shepherd, J. G. 1982. A versatile new stock-recruitment relationship for fisheries, and the construction of sustainable yield curves. Journal du Conseil international pour l'Exploration de la Mer, 40: 67-75.

Shepherd, J. G., and Cushing, D. H. 1980. A mechanism for density-dependent survival of larval fish as the basis of a stock-recruitment relationship. Journal du Conseil international pour l'Exploration de la Mer, 39: 160-167.

Shin, Y. J., and Rochet, M. J. 1998. A model for the phenotypic plasticity of North Sea herring growth in relation to trophic conditions. Aquatic Living Resources, 11: 315-324. 
Silvert, W., and Platt, T. 1980. Dynamic energy flow model of the particle size distribution in pelagic ecosystems. In Evolution and ecology of zooplancton communities, pp 754-763. Ed. by W. C. Kerfoot. University Press of New England, Hanover, NH.

Sissenwine, M. P., and Shepherd, J. G. 1987. An alternative perspective on recruitment overfishing and biological reference points. Canadian Journal of Fisheries and Aquatic Sciences, 44: 913918.

Solemdal, P. 1997. Maternal effects - a link between the past and the future. Journal of Sea Research, 37: 213-227.

Stokes, T. K., McGlade, J. M., and Law, R., eds. 1993. The exploitation of evolving resources. Lecture Notes in Biomathematics, 99, Springer-Verlag, Berlin.

Tanasichuk, R. W. 1997. Influence of biomass and ocean climate on the growth of Pacific herring (Clupea pallasi) from the southwest coast of Vancouver Island. Canadian Journal of Fisheries and Aquatic Sciences, 54: 2782-2788.

Thompson, W. F., and Bell, F. H. 1934. Biological statistics of the Pacific halibut fishery (2) ; Effect of changes in intensity upon total yield and yield per unit of gear. Report of the International fisheries (Pacific halibut) commission, 2, 49 pp.

Trippel, E. A. 1995. Age at maturity as a stress indicator in fisheries. Bioscience, 45: 759-771.

Trippel, E. A. 1998. Egg size and viability and seasonal offspring production of young Atlantic cod. Transactions of the American Fisheries Society, 127: 339-359.

Trippel, E. A., Kjesbu, O. S., and Solemdal, P. 1997. Effects of adult age and size structure on reproductive output in marine fishes. In Early life history and recruitment in fish populations, pp 29-62. Ed. by R. C. Chambers and E. A. Trippel. Fish and Fisheries Series, 21, Chapman and Hall, London. 596 pp.

Ware, D. M. 1975. Relation between egg size, growth, and natural mortality of larval fish. Journal of the Fisheries Research Board of Canada, 32: 2503-2512.

Ware, D. M. 1978. Bioenergetics of pelagic fish: theoretical change in swimming speed and ration with body size. Journal of the Fishery Research Board of Canada, 35: 220-228.

Ware, D. M. 1985. Life history characteristics, reproductive value, and resilience of Pacific herring (Clupea harengus pallasi). Canadian Journal of Fisheries and Aquatic Sciences, 42: 127-137. 


\section{Appendix}

\section{Summary of population parameters used in the study}

\section{A) Stock-specific parameters}

\begin{tabular}{|c|c|c|c|c|}
\hline Paramete & Definition & & Values & \\
\hline & & North Sea Cod & Bay of Biscay Sole & Southern Sardine \\
\hline$F_{a}$ & Fishing mortality at age & $\begin{array}{l}0.065,0.546,0.712, \\
0.637,0.591,0.672, \\
0.67,0.64,0.794,0.548\end{array}$ & $\begin{array}{l}0.0189,0.0505,0.208 \\
0.3709,0.7077,0.6046 \\
0.4735,0.5527,0.5527\end{array}$ & $\begin{array}{l}0.0673,0.1414,0.3775, \\
0.7635,0.9131,0.7635, \\
0.7635\end{array}$ \\
\hline$M_{a}$ & Natural mortality at age & $\begin{array}{l}0.8,0.35,0.25,0.2,0.2, \\
0.2,0.2,0.2,0.2,0.2\end{array}$ & 0.1 at all ages & 0.33 at all ages \\
\hline$\tilde{N}_{1}, \tilde{N}_{2}$ & $\begin{array}{l}\text { Total abundance thresholds for } \\
\text { switching population parameters }\end{array}$ & 703631431,818522160 & 241830858,285634113 & $\begin{array}{l}12011217184, \\
13718785797\end{array}$ \\
\hline $\begin{array}{l}A_{m, 3} \\
\sigma_{A_{m}, 3}\end{array}$ & $\begin{array}{l}\text { Mean and standard error of the } \\
\text { proportion mature at age in the } \\
\text { lower abundance level }\end{array}$ & $\begin{array}{l}\text { Normal distribution } \\
\mathrm{N}(3.67,1.31)\end{array}$ & $\begin{array}{l}\text { Normal distribution } \\
\mathrm{N}(2.5,0.3)\end{array}$ & $\begin{array}{l}\text { Exponential distr. } \\
\mathrm{E}(1,0.303)\end{array}$ \\
\hline$E_{3}, b_{3}$ & $\begin{array}{l}\text { Parameters of the fecundity- } \\
\text { length relationship in the lower } \\
\text { abundance level (length in } \mathrm{cm} \text { ) }\end{array}$ & $1.29,3.29$ & $0.0805,4.168$ & $5.077,3.666$ \\
\hline$W_{e, 3}$ & $\begin{array}{l}\text { Egg weight }(\mathrm{kg}) \text { in the lower } \\
\text { abundance level }\end{array}$ & 1.03E-06 & $9.66 \mathrm{E}-07$ & 1.61E-06 \\
\hline$\mu_{W_{1}}, \sigma_{W_{1}}$ & $\begin{array}{l}\text { Mean and standard deviation of } \\
\text { recruit size }(\mathrm{kg})\end{array}$ & $\begin{array}{l}0.6132,0.06155 \\
(1963-1996)\end{array}$ & $\begin{array}{l}0.00672,0.000669 \\
(1979-1996)\end{array}$ & $\begin{array}{l}0.0195,0.003567 \\
(1977-1997)\end{array}$ \\
\hline$\Delta L_{a, 3}$ & $\begin{array}{l}\text { Length increments at age }(\mathrm{cm}) \text { in } \\
\text { the lower abundance level }\end{array}$ & $\begin{array}{l}7.96,12.58,14.84 \\
13.37,6.33,4.21,3.83 \\
4.37,1.36,0.20\end{array}$ & $\begin{array}{l}7.93,6.29,4.99,3.96 \\
3.14,2.49,1.97,1.56 \\
1.24\end{array}$ & $\begin{array}{l}1.17,3.81,0.93,1.05 \\
0.58,2.20,0.30\end{array}$ \\
\hline$\alpha, \beta$ & $\begin{array}{l}\text { Parameters of the length-weight } \\
\text { relationship } W=\alpha L^{\beta} \text { (g.cm-1) }\end{array}$ & $0.0104,3.000$ & $0.00482,3.17533$ & $0.00594,3.0766$ \\
\hline$I$ & $\begin{array}{l}\text { Duration of egg incubation } \\
\text { period (days) }\end{array}$ & 20 & 9 to 15 & 5 to 6 \\
\hline$p$ & Ratio of larval to egg weight & 0.38 & 0.38 & 0.7 \\
\hline
\end{tabular}




\section{B) Early life stages parameters}

Weights are in mg wet weight.

\begin{tabular}{clcccc}
\hline Paramete & \multicolumn{1}{c}{ Definition } & & Values from sources \\
$\mathbf{r}$ & & & & & \\
& & & & & \\
(Ware, 1975) & (Beyer, 1989) & (Pepin, 1993) & (Lorenzen, 1996) \\
\hline$m$ & $\begin{array}{l}\text { Exponent of weight in growth } \\
\text { and mortality rates }\end{array}$ & 0.232 & 0.25 & 0.11 to 0.18 & 0.3 \\
\hline$r$ & Growth rate of unit weight $\left(\mathrm{d}^{-1}\right)$ & 0.2 & 0.07 & unknown & unknown \\
\hline$q$ & Mortality rate of unit weight $\left(\mathrm{d}^{-1}\right)$ & 0.14 & 0.04 & unknown & 0.08 \\
\hline
\end{tabular}

